\title{
Prefrontal consolidation supports the attainment of fear memory accuracy
}

\author{
Philip A. Vieira, ${ }^{1}$ Jonathan W. Lovelace, ${ }^{1}$ Alex Corches, ${ }^{2}$ Asim J. Rashid, ${ }^{3}$ \\ Sheena A. Josselyn, ${ }^{3}$ and Edward Korzus ${ }^{1,2}$ \\ ${ }^{1}$ Department of Psychology and Neuroscience Program, University of California Riverside, California 92521, USA; ${ }^{2}$ Biomedical \\ Sciences Program, University of California Riverside, California 92521, USA; ${ }^{3}$ Program in Neurosciences and Mental Health, \\ Hospital for Sick Children, Toronto, Ontario M5G 1X8, Canada
}

\begin{abstract}
The neural mechanisms underlying the attainment of fear memory accuracy for appropriate discriminative responses to aversive and nonaversive stimuli are unclear. Considerable evidence indicates that coactivator of transcription and histone acetyltransferase cAMP response element binding protein (CREB) binding protein (CBP) is critically required for normal neural function. CBP hypofunction leads to severe psychopathological symptoms in human and cognitive abnormalities in genetic mutant mice with severity dependent on the neural locus and developmental time of the gene inactivation. Here, we showed that an acute hypofunction of CBP in the medial prefrontal cortex (mPFC) results in a disruption of fear memory accuracy in mice. In addition, interruption of CREB function in the mPFC also leads to a deficit in auditory discrimination of fearful stimuli. While mice with deficient CBP/CREB signaling in the mPFC maintain normal responses to aversive stimuli, they exhibit abnormal responses to similar but nonrelevant stimuli when compared to control animals. These data indicate that improvement of fear memory accuracy involves mPFC-dependent suppression of fear responses to nonrelevant stimuli. Evidence from a context discriminatory task and a newly developed task that depends on the ability to distinguish discrete auditory cues indicated that CBP-dependent neural signaling within the mPFC circuitry is an important component of the mechanism for disambiguating the meaning of fear signals with two opposing values: aversive and nonaversive.
\end{abstract}

The ability to discriminate between similar, yet different, stimuli is critical for cognitive functioning ( $\mathrm{O}^{\prime}$ Reilly and McClelland 1994) and is referred to as memory specificity or memory accuracy. Failure to discriminate between aversive and nonaversive stimuli during recall may indicate decreased memory resolution (i.e., reduced access to memory details) or generalized fear or both, and may lead to inappropriate stimulus generalization. Generalization is not always inappropriate and this type of reduced fear memory accuracy is observed when one responds the same to two stimuli that are not identical. After initial generalization, fear memory accuracy can be increased through additional experiences with reinforced aversive stimulus and nonreinforced nonaversive stimulus. Conversely, overgeneralized fear is a typical symptom of anxiety disorders including phobias and posttraumatic stress disorder (PTSD), which are triggered by cues resembling traumatic experience in a secure environment (Mahan and Ressler 2012). Studies of neural substrates and mechanisms underlying memory resolution are focused on the hippocampal circuit (Leutgeb et al. 2007; Sahay et al. 2011). Recent studies also implicate prefrontal circuitry in the contextual fear memory specificity and generalization (Xu et al. 2012; Xu and Sudhof 2013) or discrimination of more discrete multiple odor stimuli (DeVito et al. 2010).

Regulatory mechanisms direct cAMP response element binding protein (CREB)-dependent transcription subsequent to learning-induced molecular changes in which neurons play a pivotal role in the conversion of short-term to long-term memory across species (Dash et al. 1990; Bourtchuladze et al. 1994; Yin et al. 1994; Josselyn et al. 2001; Kida et al. 2002; Pittenger et al.

Corresponding author: edkorzus@ucr.edu Article is online at http://www.learnmem.org/cgi/doi/10.1101/lm.036087.114.
2002). Phosphorylation of CREB at serine 133 is required for the recruitment of the chromatin remodeling factor with intrinsic acetyltransferase activity CREB binding protein (CBP), both events critical for CREB-dependent transcription (Gonzalez et al. 1989; Chrivia et al. 1993). CBP integrates multiple signaling pathways via direct interactions with independently regulated multiple transcriptional factors and components of transcriptional machinery. In addition, CBP comprises enzymatic activity referred to as HAT (histone acetyltransferase), which enables acetylation of conserved lysine amino acids on proteins by catalyzing the transfer of an acetyl group of acetyl CoA to form $\varepsilon-N$-acetyl-lysine (Bannister and Kouzarides 1996; Korzus et al. 1998). Initially, histones were considered as primary natural substrates for CBP enzymatic activity. However, histones are not the only targets for CBP's HAT activity and a number of nonhistone potential targets for CBP's HAT activity have been found, including proteins regulating chromatin remodeling and gene expression such as p53 (Gu and Roeder 1997), CREB (Lu et al. 2003), and many others (Kouzarides 2000; Sterner and Berger 2000; Yang 2004; Glozak et al. 2005; Kimura et al. 2005). Impact of histone and nonhistone protein acetylation by CBP is not fully understood. Despite uncertainty in respect to how CBP controls neuronal function via its interaction with multiple regulatory proteins and acetyltransferase activity, considerable evidence indicates that CBP is a critical component of the neural signaling underlying cognitive functioning (Alarcon et al. 2004; Korzus et al. 2004; Wood et al.

\footnotetext{
(C) 2014 Vieira et al. This article is distributed exclusively by Cold Spring Harbor Laboratory Press for the first 12 months after the full-issue publication date (see http://learnmem.cshlp.org/site/misc/terms.xhtml). After 12 months, it is available under a Creative Commons License (AttributionNonCommercial 4.0 International), as described at http://creativecommons. org/licenses/by-nc/4.0/.
} 
2005; Chen et al. 2010; Barrett et al. 2011; Valor et al. 2011, 2013; Peixoto and Abel 2012; Maddox et al. 2013). However, it is difficult to separate developmental defects, compensatory developmental effects, and acute function in the adult brain of a gene with pronounced developmental functions. To avoid developmental confounds, four independent manipulations to down-regulate $\mathrm{CBP}$ acetyltransferase activity specifically in the adult living brain have been reported to date. Acute CBP hypofunction targeted specifically in adult mice by means of Tet-regulatable expression of CBP $\Delta \mathrm{HAT}$ targeted to excitatory forebrain neurons (Korzus et al. 2004) or hippocampal focal knockout of CBP (Barrett et al. 2011) or intra lateral amygdala infusion of c646, a selective pharmacological inhibitor of p300/CBP activity, shortly following fear conditioning (Maddox et al. 2013) resulted in selective impairment of long-term potentiation (Barrett et al. 2011; Maddox et al. 2013) and long-term memory (Korzus et al. 2004; Barrett et al. 2011; Maddox et al. 2013). In addition, ablation of CBP in the adult brain resulted in impaired environmental enrichment-induced neurogenesis (Lopez-Atalaya et al. 2011), which suggests an additional role of CBP in adult neurogenesis-dependent enhancement of adaptability toward novel experiences (Aimone et al. 2011; Sahay et al. 2011). These data strongly implicate CBP acetyltransferase activity in neural epigenetic signaling underlying long-term memory consolidation.

Although there has been extensive research into the function of the PFC during information acquisition and retrieval, a fundamental question that has escaped resolution is whether CBP-dependent signaling within the prefrontal cortex supports mechanisms in which fear memories are encoded and retrieved without confusion. Using mutant mice expressing dominant negative CBP with eliminated acetyltransferase activity, we have tested the impact of CBP-dependent mechanisms in the mPFC on fear memory accuracy. Evidence from context and auditory discriminatory tasks indicated that the MPFC circuitry is critical for the acquisition of fear memory accuracy necessary for the recognition of subtle differences between aversive and nonaversive stimuli. These data indicate that CBP-dependent signaling in the mPFC is critical for the suppression of fear responses to nonrelevant stimuli, which is a necessary process toward improvement of fear memory accuracy.

\section{Results}

\section{Impairment of contextual fear memory specificity in $\mathrm{CBP} \Delta \mathrm{HAT}^{\mathrm{PFC}}$ mice}

The CBP $\Delta$ HAT mutant, a dominant-negative inhibitor of CBPdependent lysine acetylation, harbors a substitution mutation of two conserved residues ( $\mathrm{Tyr}^{1540} / \mathrm{Phe}^{1541}$ to $\mathrm{Ala}^{1540} / \mathrm{Ala}^{1541}$ ) in the acetyl CoA binding domain (Korzus et al. 1998, 2004). This mutant has no intrinsic acetyltransferase activity due to its inability to interact with a donor of acetyl group, acetyl-CoA, but it retains all protein-protein interaction domains (Korzus et al. 1998). When expressed acutely in adult excitatory neurons, CBPAHAT functions as a specific blocker of long-term memory consolidation without affecting information acquisition or short-term memory (Korzus et al. 2004). To test the impact of CBP-dependent signaling in the medial prefrontal cortex (mPFC) on fear memory specificity, we generated mice expressing CBPAHAT and eGFP in the $\mathrm{mPFC}$ using virus-mediated gene transfer (referred to as CBPAHAT ${ }^{\mathrm{PFC}}$ mice) (Fig. 1A). For control mice, we injected virus-expressing eGFP only in the mPFC. Cytohistological analysis of brain tissue isolated from CBPAHAT ${ }^{\mathrm{PFC}}$ and control animals revealed that the majority of cells expressing mutant protein in the $\mathrm{mPFC}$ were neurons (Ctrl, $93.85 \pm 0.006 \%, n=3$;
$\mathrm{CBP} \Delta \mathrm{HAT}^{\mathrm{PFC}}, 92.06 \pm 0.012 \%, n=3 ; t_{(2)}=-0.03, P=0.511, r=$ 0.013 ; data not shown). Conditioned CBP $\Delta \mathrm{HAT}^{\mathrm{PFC}}$ mice display decreased levels of acetylated histone H3 ( $t$-test, $t_{(10)}=2.38, P=$ $0.0382, r=0.6013 ;$ Ctrl, $1 \pm 0.06, n=5 ; \mathrm{CBP} \Delta \mathrm{HAT}^{\mathrm{PFC}}, 0.74 \pm$ $0.06, n=7$ ) and acetylated histone $\mathrm{H} 4$ (Ac-H4 [right panel], $t$-test, $t_{(10)}=2.9718, P=0.0140, r=0.6848$; Ctrl, $1 \pm 0.04, n=6$;

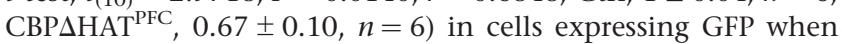
compared to conditioned control animals (Fig. 1B). These data are consistent with previous studies reporting decreased levels of acetylated histones in CBP mutant mice (Alarcon et al. 2004; Wood et al. 2005; Chen et al. 2010; Barrett et al. 2011; Valor et al. 2011; Peixoto and Abel 2012).

We examined CBP $\Delta \mathrm{HAT}^{\mathrm{PFC}}$ mice using the fear-conditioning paradigm (Fig. 1C). CBP $\Delta \mathrm{HAT}^{\mathrm{PFC}}$ mice performed similarly to controls in the contextual version of the fear conditioning task after a 24-h delay (Ctrl, 25.78\%, $n=10$; CBP $\Delta$ HAT $^{\text {PFC }}$, $22.14 \%, n=10 ; t_{(18)}=1.28, P=0.108$ ) (Fig. 1C). To determine whether the mPFC supports fear memory accuracy, we examined $\mathrm{CBP} \triangle \mathrm{HAT}^{\mathrm{PFC}}$ mice using the context fear discrimination task (Fig. 1D; Lovelace et al. 2014). First, we tested CBP $\Delta$ HAT $^{\mathrm{PFC}}$ and control mice on a generalization task, in which we examined the freezing responses to novel context $\mathrm{B}$ after training on the fear conditioning task to context A. Context B was similar yet not identical to the training context $\mathrm{A}$ (see Materials and Methods). We found no difference in freezing responses to context $\mathrm{B}$ or $\mathrm{A}$ in $\mathrm{CBP} \triangle \mathrm{HAT}^{\mathrm{PFC}}$ and control mice (Context $\mathrm{A}$ vs. $\mathrm{B}$ t-test: Ctrl, $\left.n=9, P=0.805 ; \mathrm{CBP} \Delta \mathrm{HAT}^{\mathrm{PFC}}, n=11, P=0.851\right)$ (Fig. 1E). Thus, CBP $\Delta$ HAT $^{\mathrm{PFC}}$ mice did not demonstrate any obvious abnormalities in fear memory generality during the initial presentation of novel context $\mathrm{B}$. Next, CBPAHAT ${ }^{\mathrm{PFC}}$ mice and control littermates were trained to distinguish between the conditioned context A, which was paired with a foot shock (CS+), and an unconditioned context $\mathrm{B}$, which was not paired with any reinforcement (CS-), over multiple training sessions (Fig. 1D). This task requires temporal integration because animals learn subtle differences between context A and B over many days with a single exposure to each context only once per day. Initially, the control and CBPAHAT ${ }^{\mathrm{PFC}}$ mice generalized their conditioned responses and exhibited similar freezing levels to both the CS+ and CS- contexts (Block Trials 1-4). However, the control animals began to freeze significantly less in response to context $\mathrm{B}$ compared to context A after four block trials of training, demonstrating the ability to consistently distinguish between similar yet different contexts (Block Trials 5-6) (RM-ANOVA of trial block and context: Context, $F_{(1,8)}=9.423, P=0.015$; Trial Block, $F_{(5,40)}=3.24, P=0.015$; Trial Block $\times$ Context, $F_{(5,40)}=6.58, P=$ $0.0001 ; n=9$ ) (Fig. 1F). Post hoc analysis using Bonferroni correction for multiple comparisons indicated that differences were present during Trial Blocks $5(P=0.003)$ and $6(P=0.005)$. In contrast to the control animals, $\mathrm{CBP} \Delta \mathrm{HAT}^{\mathrm{PFC}}$ mice failed to distinguish between context $\mathrm{A}$ and $\mathrm{B}$ and continued to generalize their conditioned responses throughout all $12 \mathrm{~d}$ of training (RM-ANOVA of trial block and context: Context, $F_{(1,10)}=5.42$, $P=0.04$; Trial Block, $F_{(2,15)}=11.09, P=0.002$; Trial Block $\times$ Context, $\left.F_{(3,27)}=1.62, P=0.21 ; n=11\right)$ (Fig. 1G). These data demonstrated that CBP $\triangle \mathrm{HAT}$ expressed in the $\mathrm{mPFC}$ resulted in imbalanced neural processes underlying fear memory specificity and generalization. Analysis of the context discrimination ratio confirmed that at the end of the training, the control animals performed better on the context discrimination task compared to the $\mathrm{CBP} \Delta \mathrm{HAT}^{\mathrm{PFC}}$ mice. Figure $1 \mathrm{H}$ shows no difference in performance between control and CBP $\Delta H_{A T}{ }^{\mathrm{PFC}}$ animals on Trial Block 1 ( $t$-test, $\left.t_{(18)}=0.02, P=0.99, r=0.005\right)$, but a marked difference on Trial Block 6 ( $t$-test, $\left.t_{(18)}=2.60, P=0.018, r=0.52\right)$. These findings demonstrate that $\mathrm{CBP} \triangle \mathrm{HAT}^{\mathrm{PFC}}$ mice have a strong deficit in context discrimination. 
Hypothetically, learning of appropriate responses to fearful and similar but not relevant stimuli may involve changes in response to aversive stimuli or nonaversive or both across the entire training. Therefore we analyzed fear responses to Context $\mathrm{A}(\mathrm{CS}+)$ and, separately, to Context $\mathrm{B}(\mathrm{CS}-)$ in $\mathrm{CBP} \Delta \mathrm{HAT}^{\mathrm{PFC}}$ and control mice. There was no difference in responses to conditioned stimuli $\mathrm{CS}+$ between $\mathrm{CBP} \Delta \mathrm{HAT}^{\mathrm{PFC}}$ and control mice across the entire context discrimination training (RM-ANOVA of Trial Blocks 1-5 and group: Trial Block $\times$ Group, $F_{(2.7,47.9)}=$ 1.782, $P=0.169$ ) (Fig. $1 \mathrm{~F}, \mathrm{G})$. However, $\mathrm{CBP} \Delta \mathrm{HAT}^{\mathrm{PFC}}$ and control mice responded differently to nonrelevant stimuli CS - across training on the context discriminatory task (RM-ANOVA of Trial Blocks $1-5$ and group: Trial Block $\times$ Group, $F_{(2.9,51.6)}=4.919$, $P=0.005$ ) (Fig. 1F,G). Change in freezing to CS - across the training (freezing $\Delta$ ) was significantly higher in $\mathrm{CBP} \Delta \mathrm{HAT}^{\mathrm{PFC}}$ when compared to control mice ( $t$-test, $t_{(18)}=-2.235, P=0.038$ ) (Fig. 1I). However, calculations of freezing $\Delta$ consider only performance on Trial Blocks 1 and 6. In order to include performance of tested animals on each day across the entire training on the contextual discriminatory task (Trial Blocks 1-6) (Fig. 1F,G), we compared average slopes $(\alpha)$ of fitted learning curves (Fig. $1 \mathrm{~J})$. The learning of appropriate responses to CS + shows a positive slope in both control $(\alpha=4.76 \pm 1.07$, where $\alpha=$ slope $)$ and $\mathrm{CBP} \Delta \mathrm{HAT}^{\mathrm{PFC}}(\alpha=6.35 \pm 1.61)$ mice and there is no difference between groups ( $t$-test, $\left.t_{(18)}=-0.778, \quad P=0.446\right)$. The learning of appropriate response to CSshows a negative slope in the control group ( $\alpha=-0.88 \pm 1.34)$, which significantly improved fear memory accuracy at the end of training (Fig. 1F). In contrast, the CBPAHAT ${ }^{\mathrm{PFC}}$ group, which failed to improve fear memory accuracy across training (Fig. 1G), showed a positive slope for CS $-(\alpha=4.26 \pm 1.4)$, a marked difference from control responses to the CS $-(\mathrm{CS}-/ \mathrm{Ctrl}, \alpha=-0.88 \pm 1.34$; $\mathrm{CS}-/ \mathrm{CBP} \Delta \mathrm{HAT}^{\mathrm{PFC}}, \alpha=4.26 \pm 1.4$; $\mathrm{CS}-$ slope/Ctrl vs. CBP $\triangle$ HAT $^{\mathrm{PFC}} t$-test, $\left.t_{(18)}=-2.614, P=0.018\right)$. In summary, analysis of patterns of responses to Context $\mathrm{A}(\mathrm{CS}+)$ and Context B (CS-) in control animals revealed that the improvement of contextual fear memory accuracy was due to increased freezing behavior to the CS+ and a decrease in freezing to CS-. CBP hypofunction in the mPFC altered the ability to learn discriminatory responses to $\mathrm{CS}+\mathrm{vs}$. CS by disrupting the pattern of the learning curve for CS - only. These data suggest that the mPFC supports the improvement of contextual fear memory accuracy by controlling the acquisition of appropriate responses to nonrelevant stimuli.

We also found that $\mathrm{CBP} \Delta \mathrm{HAT}^{\mathrm{PFC}}$ mice performed similar to controls in the cued version of the fear conditioning task during acquisition (data not shown, $\left.F_{(5,90)}=1.49, P=0.201\right)$ and after a 24-h delay (Ctrl, $47.17 \pm 5.82 \%, n=10$; $\mathrm{CBP} \mathrm{HAT}^{\mathrm{PFC}}, \quad 57.27 \pm 7.21 \%, \quad n=10$; $\left.t_{(18)}=-1.042, \quad P=0.324, \quad r=-0.096\right)$

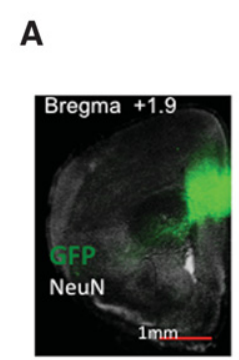

D
(Fig. 2A). These data indicate that information acquisition and long-term memory examined with a 24-h delay on contextual (Fig. 1C) and cued fear-conditioning (Fig. 2A [and also see Fig. $4 \mathrm{~A}, \mathrm{~B}]$ ) were normal in $\mathrm{CBP} \Delta \mathrm{HAT}^{\mathrm{PFC}}$ mice. The normal performance of $\mathrm{CBP} \Delta \mathrm{HAT}^{\mathrm{PFC}}$ on these fear-conditioning tasks (Figs. 1C and 2A [and also see Fig. 4A,B]) indicates that $\mathrm{CBP} \Delta \mathrm{HAT}^{\mathrm{PFC}}$ mice have functioning circuitry underlying Pavlovian conditioning.

CBPAHAT ${ }^{\mathrm{PFC}}$ mice showed normal levels of locomotor activity (Total Distance Traveled: Ctrl, $46159.94 \pm 1335 \mathrm{~mm}, n=$ 12; CBP $\Delta \mathrm{HAT}^{\mathrm{PFC}}, 43563.67 \pm 4730.60 \mathrm{~mm}, n=16 ; t_{(11)}=-0.43$, $P=0.6627, r=0.1289$. Average Velocity: Ctrl, $51.52 \pm 1.50$ $\mathrm{mm} / \mathrm{sec}, n=12 ; \mathrm{CBP} \mathrm{HAT}^{\mathrm{PFC}}, 48.43 \pm 5.23 \mathrm{~mm} / \mathrm{sec}, n=16$; $t_{(11)}=-0.367, P=0.6399, r=0.1101$ ) (Fig. 2B,C) and normal anxiety-related responses (Thigmotaxis: Ctrl, $58.58 \pm 4.12 \%, n=$ 12 ; $\mathrm{CBP} \Delta \mathrm{HAT}^{\mathrm{PFC}}, 66.37 \pm 6.14 \%, n=16 ; t_{(11)}=0.34, P=0.3689$, $r=0.1030)$ (Fig. 2D).
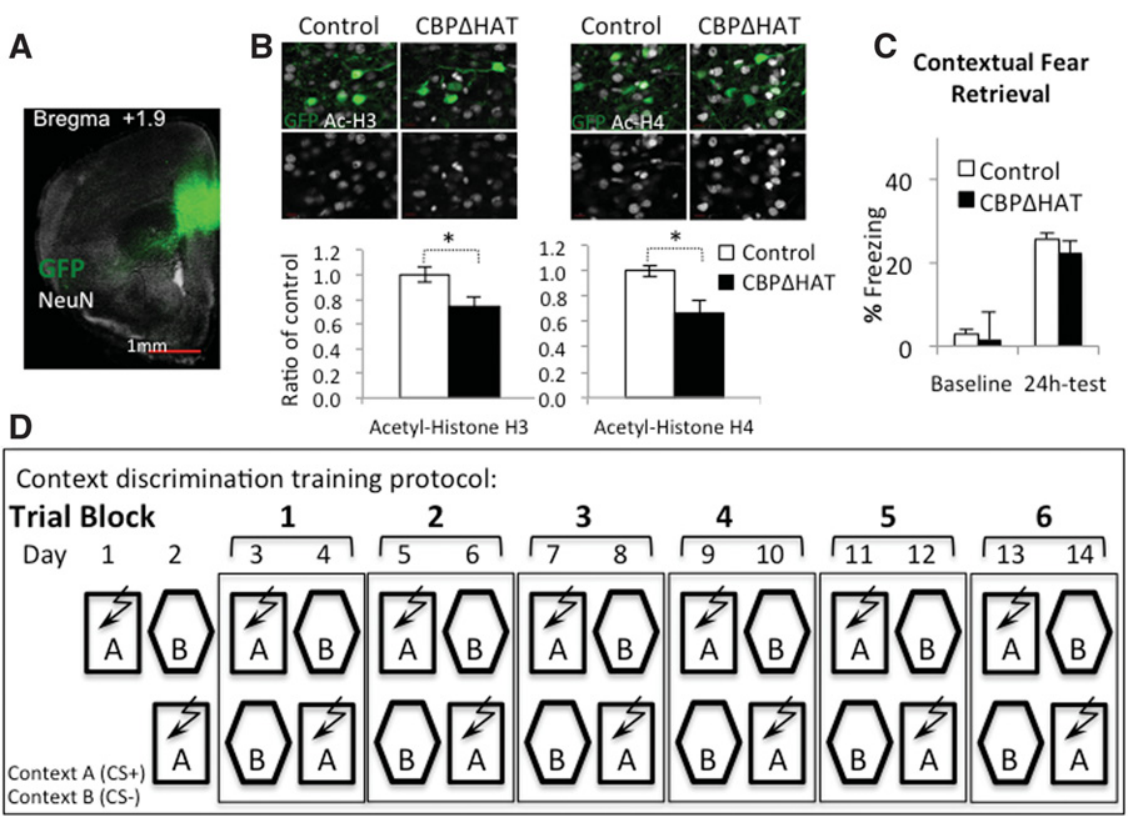

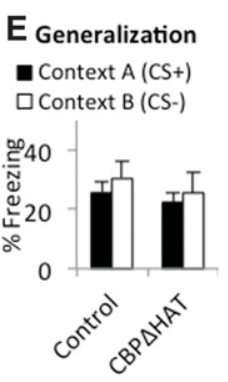

I Freezing delta

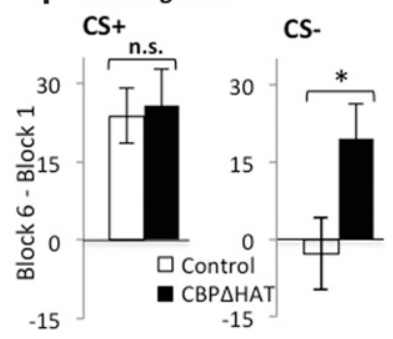

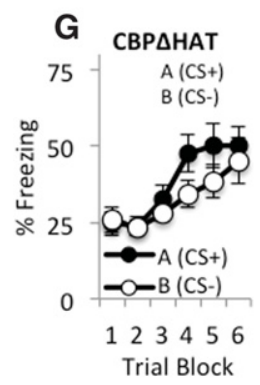

H Discrimination Index

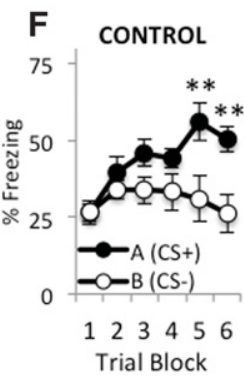

J Average learning curves
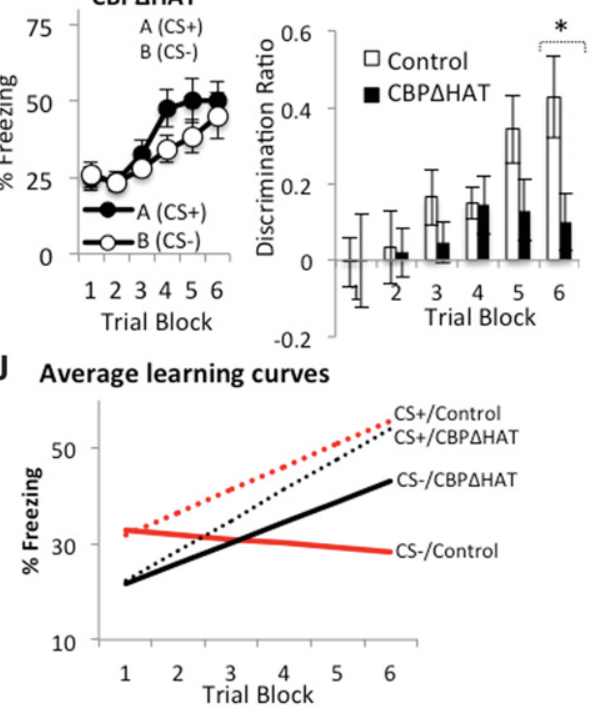

Figure 1. (Legend on next page) 


\section{Impairment of auditory memory specificity in $\mathrm{CBP} \triangle \mathrm{HAT}^{\mathrm{PFC}}$ mice}

To evaluate if the deficient discrimination of aversive and nonaversive external stimuli was sensory input-specific, we examined $\mathrm{CBP} \Delta \mathrm{HAT}^{\mathrm{PFC}}$ mice using a novel auditory discrimination task, which tests the ability of subjects to recognize the direction of frequency modulated (FM)-sweeps (trains of upward and downward FM-sweeps) (Fig. 3). This assay includes $3 \mathrm{~d}$ of acquisition (single $\mathrm{CS}+$ foot shock pairing) followed by a 24 -h test on Day 4 and a generalization test on Days 4-5. Discrimination training takes place on Days 7-12 in which animals are run through three sessions: first, they are tested for freezing to $\mathrm{CS}+$ and $\mathrm{CS}-$ (in context $\mathrm{C})$; second, they are exposed to $\mathrm{CS}+($ or $\mathrm{CS}-$ ); third, they are exposed to $\mathrm{CS}-$ (or $\mathrm{CS}+$ ).

In parallel experiments, we also microinjected into the $\mathrm{mPFC}$ an HSV virus encoding a mutant form of CREB (mCREB) and tested these mice (mCREB ${ }^{\mathrm{PFC}}$ ) in the auditory discrimination task. CREB is implicated in memory consolidation across a variety of species (Dash et al. 1990; Bourtchuladze et al. 1994; Yin et al. 1994; Josselyn et al. 2001; Kida et al. 2002; Pittenger et al. 2002) and functions immediately upstream of CBP. mCREB (CREB ${ }^{\text {S133A }}$ mutation) cannot be phosphorylated at the key serine 133 residue and, therefore, cannot recruit $\mathrm{CBP}$ and activate transcription (Gonzalez et al. 1989; Chrivia et al. 1993). Thus we have tested a possible involvement of this well-recognized mediator of memory consolidation in auditory fear discrimination in parallel experiments to those performed in CBP $\Delta \mathrm{HAT}^{\mathrm{PFC}}$ mice.

We first examined FM-sweep fear conditioning acquisition in $\mathrm{CBP} \triangle \mathrm{HAT}^{\mathrm{PFC}}$ and $\mathrm{mCREB}^{\mathrm{PFC}}$ mice. All three groups: the $\mathrm{CBP}_{\mathrm{H}} \mathrm{HAT}^{\mathrm{PFC}}, \mathrm{mCREB}^{\mathrm{PFC}}$, and control mice similarly acquired this form of Pavlovian conditioning (RM-ANOVA of Day and Group, $F_{(4,82)}=0.975, P=0.426$ ) (Fig. $4 \mathrm{~A}$ ) and showed the same performance on the 24-h memory test (two way ANOVA of Group and Baseline/24 h-Test: Group, $F_{(2,82)}=0.777, P=0.463$; Baseline $/ 24$-h Test, $F_{(1,82)}=688.3, P=1.2 \times 10^{-41}$; Group $\times$ Baseline/24-h Test, $\left.F_{(2,82)}=0.205, P=0.815\right)$ (Fig. 4B). These data demonstrate that information acquisition and long-term memory tested after a 24-h delay on FM-sweep fear conditioning was normal in CBPAHAT ${ }^{\mathrm{PFC}}$ and $\mathrm{mCREB}^{\mathrm{PFC}}$ mice. We also tested $\mathrm{CBP} \triangle \mathrm{HAT} \mathrm{PFC}^{\mathrm{PF}}, \mathrm{mCREB}^{\mathrm{PFC}}$, and control mice on generalization tasks, in which we examined their freezing responses to novel downward FM-sweep (CS-) after training on the upward FM-sweep (CS+) fear conditioning task. The generalization test revealed that there was no difference in the freezing responses to the $\mathrm{CS}-$ or $\mathrm{CS}+$ between $\mathrm{CBP} \Delta \mathrm{HAT}^{\mathrm{PFC}}, \mathrm{mCREB}^{\mathrm{PFC}}$, and control mice (ANOVA of FM-sweep direction and group during Days 4 and 5: Group, $F_{(2,82)}=0.37, \quad P=0.692 ; \quad$ ANOVA of FM-sweep direction, $F_{(1,82)}=3.458, P=$ 0.067; Group $\times$ FM-Sweep Direction, $\left.F_{(2,82)}=0.090, \quad P=0.914\right) \quad($ Fig. $4 \mathrm{C})$. These data indicate that strong generalization was observed during Days 4 and 5 in all three tested groups.

Next, the animals underwent auditory discrimination training (Fig. 4D-F). Initially, the control, CBPAHAT ${ }^{\mathrm{PFC}}$ and mCREB $^{\text {PFC }}$ mice generalized their conditioned responses and exhibited similar levels of freezing responses to both CS+ and CS - (Days 1-2). However, after $2 \mathrm{~d}$ of training, the control animals exhibited a higher number of freezing responses to CS + and significantly fewer freezing responses to $\mathrm{CS}$ - compared to $\mathrm{CS}+$, demonstrating the ability to consistently distinguish between similar yet different auditory patterns (Days 9-12) (RMANOVA of Day and FM-sweep direction: Day $\times$ FM-sweep direction, $F_{(2.2,33.5)}=$ 10.776, $P=0.0002, n=16$ ) (Fig. $4 \mathrm{D}$ ). Post hoc analysis using Bonferroni correction $(\alpha=0.0083)$ for multiple comparisons indicated that differences were present during Days 9 (CS+ vs. CS $t$-test, $\left.t_{(30)}=3.632, P=0.001, r=0.55\right)$, $10\left(t_{(30)}=5.227, P=0.00001, r=0.69\right)$, $11\left(t_{(30)}=7.540, \quad P=2.1 \times 10^{-08}, \quad r=\right.$ $0.81)$, and $12\left(t_{(30)}=9.253, P=2.7 \times\right.$ $\left.10^{-10}, r=0.86\right)$ only.

CBP $\triangle H_{A T}{ }^{\mathrm{PFC}}$ mice demonstrated weak ability to discriminate between $\mathrm{CS}+$ and $\mathrm{CS}-$, and only during the last $2 \mathrm{~d}$ of training (RM-ANOVA of Day and FM-sweep direction: Day $\times$ FM-sweep direction, $F_{(5,70)}=5.071, P=0.001, n=$ 15) (Fig. 4E). Post hoc analysis using Bonferroni correction for multiple 
A

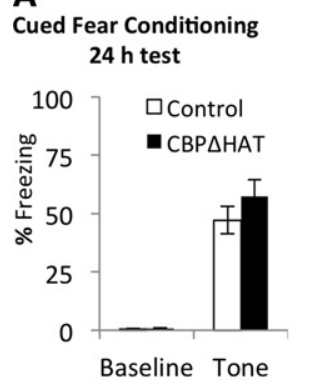

B

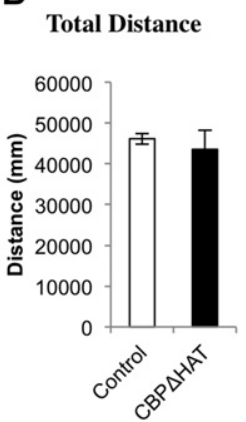

C

Average Velocity

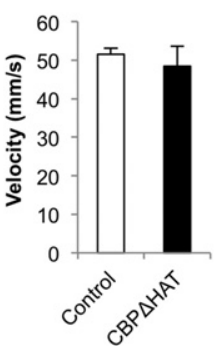

D Thigmotaxis

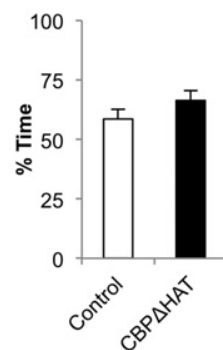

Figure 2. Pavlovian fear conditioning and locomotor activity are normal in CBP $\triangle H A T^{\mathrm{PFC}}$ mice. $(A)$ Pavlovian cued fear conditioning was normal in CBPAHAT ${ }^{\mathrm{PFC}}$ mice. CBP $\triangle H A T^{\mathrm{PFC}}$ and control (Ctrl) mice showed normal acquisition and retention of contextual fear conditioning. Contextual fear was tested in context A at $24 \mathrm{~h}$ after the five CS-US pairing (CS, $2 \mathrm{sec}, 2800-\mathrm{Hz}$ tone; US, -foot shock). $\mathrm{CBP} \triangle \mathrm{HAT} \mathrm{T}^{\mathrm{PFC}}$ mice, $n=10$. Control, $n=10$. $(B, C)$ Noninduced locomotor activity and $(D)$ anxietyrelated responses were unaltered in $\mathrm{CBP} \triangle \mathrm{HAT} \mathrm{P}^{\mathrm{PFC}}$ mice.

comparisons indicated that differences were present during Days $11\left(\mathrm{CS}+\right.$ vs. CS $-t$-test, $\left.t_{(28)}=3.149, P=0.004, r=0.51\right)$ and 12 $\left(t_{(28)}=3.325, P=0.002, r=0.53\right)$ only. In contrast to the control animals, CBP $\triangle \mathrm{HAT}^{\mathrm{PFC}}$ mice continued to generalize their conditioned responses after $2 \mathrm{~d}$ of training and failed to distinguish between context A and B during Days 9 and 10 (Day 9, $P=0.286$; Day $10, P=0.291)$.

Clearly, CBP $\triangle \mathrm{HAT}^{\mathrm{PFC}}$ mice demonstrated a strong deficit in auditory memory specificity when compared to controls (RM-ANOVA of Group and FM-sweep direction and Days 712: Group $\times$ FM-sweep direction $\times$ Day, $F_{(2.8,81.4)}=3.033, P=$ 0.037; Group $\times$ FM-sweep direction, $F_{(1,29)}=7.86, P=0.009$; $\mathrm{CBP} \Delta \mathrm{HAT}^{\mathrm{PFC}}, n=15$; Ctrl, $n=16$ ) (Fig. $4 \mathrm{D}, \mathrm{E}$ ). Furthermore, analysis of discrimination ratios shows a difference in performance between control and CBP $\Delta \mathrm{HAT}^{\mathrm{PFC}}$ animals on Days 10-12 (Discrimination Index CBP $\Delta \mathrm{HAT}^{\mathrm{PFC}}$ vs. Ctrl $t$-test: Day 10, $t_{(29)}=2.813, P=0.0087, r=0.46 ;$ Day $11, t_{(29)}=3.546, P=$ $0.001, \quad r=0.55 ; \quad$ Day $12, t_{(29)}=3.643, \quad P=0.001, \quad r=0.56$; $\mathrm{CBP} \Delta \mathrm{HAT}^{\mathrm{PFC}}, n=15$; Ctrl, $n=16$ ) (Fig. $4 \mathrm{G}$ ) but not during the initial phase of training. Clearly, control mice show better performance than $\mathrm{CBP} \triangle \mathrm{HAT}^{\mathrm{PFC}}$ mice on auditory discrimination (Fig. 4D,E,G). Taken together, these data demonstrate that $\mathrm{CBP} \triangle \mathrm{HAT}$ expressed in the mPFC resulted in abnormal auditory (FM-sweep direction) fear memory specificity.

Similarly to CBP $\triangle H_{A T}{ }^{\mathrm{PFC}}$ animals, $\mathrm{mCREB}^{\mathrm{PFC}}$ mice demonstrated a strong deficit in memory specificity during the discrimination phase when compared to controls on the auditory discrimination task (RM-ANOVA, Group $\times$ FM-sweep direction $\times$ Day: $F_{(2.8,79.6)}=4.644, P=0.006 ; \mathrm{mCREB}^{\mathrm{PFC}}, n=14 ; \mathrm{Ctrl}, n=16$ ) (Fig. 4F). These data demonstrated that mCREB $^{\text {PFC }}$ expressed in the mPFC prevented an improvement of auditory memory accuracy across the training as observed in control mice (Fig. 4D). Analysis of the auditory discrimination ratio confirmed that at the end of the training, the control animals performed better on the auditory discrimination task compared to the $\mathrm{MCREB}^{\mathrm{PFC}}$ mice (RM-ANOVA of Day and Group: Day $\times$ Group, $F_{(2.5,69.0)}=$ 5.149, $P=0.005$; $\mathrm{mCREB}^{\mathrm{PFC}}, n=14$; Ctrl, $n=16$ ) (Fig. $4 \mathrm{H}$ ). Furthermore, analysis of discrimination ratios showed a strong difference in performance between control and $\mathrm{mCREB}^{\mathrm{PFC}}$ animals on Days 10-12 ( $t$-test: Day $10, t_{(28)}=2.232, P=0.034, r=$ 0.39; Day 11, $t_{(28)}=4.130, P=0.0003, r=0.62$; Day 12, $t_{(28)}=$ 4.313, $\left.P=0.0002, r=0.63 ; \mathrm{mCREB}^{\mathrm{PFC}}, n=14 ; \mathrm{Ctrl}, n=16\right)$.

Next, we performed an analysis of fear responses to upsweep (CS+) and, separately, to downsweep (CS - ) in control, CBP $\triangle \mathrm{HAT}^{\mathrm{PFC}}$, and $\mathrm{mCREB}^{\mathrm{PFC}}$ mice tested on FM-sweep direc-

in freezing responses to $\mathrm{CS}+$ in $-0.278 \pm 1.15$ ) across the entire FM-sweep 位 ence in the learning (slopes) of appropriate responses to CS+ between CBPAHAT ${ }^{\mathrm{PFC}}$ and control groups (CS+ slope/Ctrl vs. CBPAHAT ${ }^{\mathrm{PFC}} t$-test, $t_{(29)}=-0.015, P=0.988$ ) (Fig. $4 \mathrm{~J}$ ) or mCREB $^{\mathrm{PFC}}$ and control mice $\left(\mathrm{CS}+\right.$ slope/Ctrl vs. mCREB ${ }^{\mathrm{PFC}}$ $t$-test, $t_{(28)}=1.906, P=0.067$ ) (Fig. $4 J$ ). However, CBP $\Delta \mathrm{HAT}^{\mathrm{PFC}}$ and mCREB $^{\mathrm{PFC}}$ mice responded differently to nonrelevant stimuli CS - across training on the auditory discriminatory task when compared to normal mice (CS $-/ \mathrm{CBP} \Delta \mathrm{HAT} \mathrm{T}^{\mathrm{PFC}}$ vs. Ctrl, RM-ANOVA of Days $1-5$ and group, Day $\times$ Group, $F_{(3.8,111,4)}=$ $6.151, P=0.0002$; CS $-/ \mathrm{mCREB}^{\mathrm{PFC}}$ vs. Ctrl, RM-ANOVA of Days $1-5$ and group, Day $\times$ Group, $\left.F_{(3.7,103.8)}=5.685, P=0.0005\right)$ (Fig. 4D,E). When compared to control mice, change in freezing (freezing $\Delta$ ) to CS - across the training was also significantly different in CBP $\Delta \mathrm{HAT}^{\mathrm{PFC}}$ ( $t$-test, $t_{(29)}=-2.798, P=0.009$ ) (Fig. $4 \mathrm{I})$ and in $\mathrm{mCREB}^{\mathrm{PFC}}$ mice $\left(t\right.$-test, $t_{(28)}=-2.466, P=0.02$ ) (Fig. $4 \mathrm{I})$. The marked improvement of discrimination observed on the FM-sweep direction fear discriminatory task in control mice

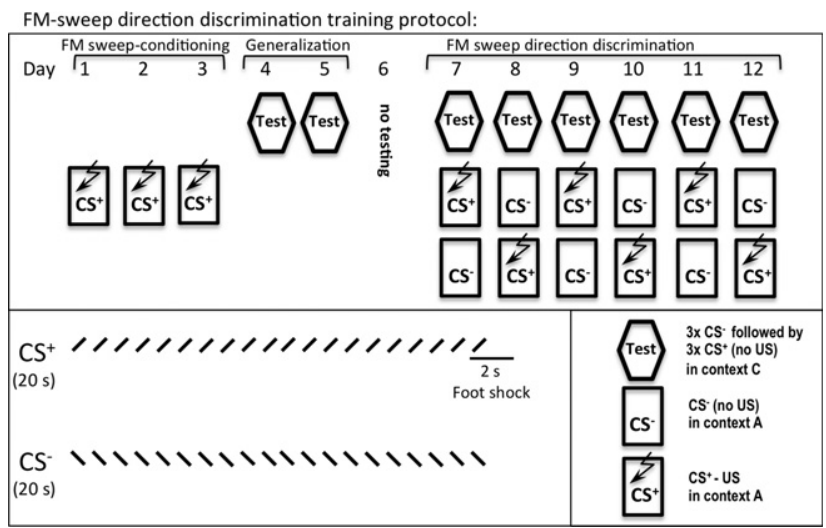

Figure 3. Experimental design for the auditory discrimination test. The auditory discrimination task tests the ability of subjects to recognize a direction of FM-sweeps (trains of upward and downward FM-sweeps). The conditioned stimuli (CS) for auditory fear conditioning were 20 -sec trains of FM-sweeps for a 400-msec duration, logarithmically modulated between 2 and $13 \mathrm{kHz}$ (upsweep) or 13 and $2 \mathrm{kHz}$ (downsweep) delivered at $1 \mathrm{~Hz}$ at $75 \mathrm{~dB}$. As described in Materials and Methods, these assays include three phases: FM-sweep conditioning (Days 1-3), generalization (Days 4-5), and FM-sweep direction discrimination training (Days 6-12). 
(Fig. 4D,G,J) coincides with the significant negative slope of the learning curve for CS $-(\alpha=-6.176 \pm 1.22)$ (Fig. 4J). The $\mathrm{CBP} \Delta \mathrm{HAT}^{\mathrm{PFC}}$ group, which failed to improve fear memory accuracy across training (Fig. 4E,G), shows only a slight negative slope for CS - across the training $(\alpha=-1.22 \pm 0.78)$ (Fig. 4J) and a marked difference when compared to the CS - slope observed in control animals (CS - slope/Ctrl vs. CBP $\Delta H_{A} T^{\mathrm{PFC}} t$-test, $t_{(29)}=-3.368, P=0.002$ ) (Fig. 4J). The mCREB $^{\text {PFC }}$ group, which did not improve performance on the auditory discrimination task as well (Fig. 4F,H), exhibited similar patterns of learning to the CBP $\triangle \mathrm{HAT}^{\mathrm{PFC}}$ mice. While responses to CS+ do not vary from those observed for control mice (Fig. 4I,J), the CS - learning curve is significantly different in mCREB $^{\mathrm{PFC}}$ mice compared to control mice $\left(\mathrm{CS}-/ \mathrm{Ctrl}, \alpha=-6.176 \pm 1.22 ; \mathrm{CS}-/ \mathrm{mCREB}^{\mathrm{PFC}}\right.$, $\alpha=-0.746 \pm 1.03 ; \mathrm{CS}-$ slope/Ctrl vs. $\mathrm{mCREB}^{\mathrm{PFC}} t$-test, $t_{(28)}=-3.347, P=0.002$ ) (Fig. 4J).

In summary, analysis of patterns of responses to $\mathrm{CS}+$ and $\mathrm{CS}$ - in control animals tested on the FM-sweep direction fear discriminatory task revealed that the improvement of auditory fear memory accuracy was due to only a slight incline in freezing to $\mathrm{CS}+$ and rapid decline in freezing to $\mathrm{CS}-$. CBP hypofunction or CREB hypofunction in the mPFC altered the ability to learn auditory discriminatory responses to CS+ vs. CS - by disrupting the pattern of learning for CS- only, while responses to $\mathrm{CS}+$ remained similar to those of control mice. Consistent with conclusions regarding contextual fear memory specificity, these data demonstrate that the mPFC supports the improvement of auditory fear memory accuracy by controlling acquisition of appropriate responses to nonrelevant stimuli.

\section{Discussion}

The present findings are the first evidence of the critical role that the mPFC plays in the attainment of fear memory accuracy for appropriate discriminative responses to aversive and nonaversive stimuli. They add substantially to the understanding of the circuitry and molecular mechanisms underlying fear memory specificity and generalization. We demonstrated that CBP-dependent signaling in the $\mathrm{mPFC}$ is required for fear memory accuracy. In addition, fear memory accuracy was also abnormal in mutant mice with disrupted CREB function, which is one of the most widely studied mediators of cellular memory consolidation in Drosophila, Aplysia, and mice (Dash et al. 1990; Bourtchuladze et al. 1994; Yin et al. 1994; Josselyn et al. 2001; Kida et al. 2002; Pittenger et al. 2002). The requirement of CBP acetyltransferase activity for memory consolidation has been demonstrated before, including acetylation/deacetylation-targeted pharmacological rescue of memory consolidation in CBP $\triangle$ HAT mutant mice (Alarcon et al. 2004; Korzus et al. 2004) or latephase LTP in CBP deficient mutant mice (Alarcon et al. 2004), and also in Aplysia (Guan et al. 2002).
It is important to note that Pavlovian auditory and contextual fear conditioning were intact in $\mathrm{CBP} \Delta \mathrm{HAT}^{\mathrm{PFC}}$ and $\mathrm{mCREB}^{\mathrm{PFC}}$ mice. Memory generalization measured immediately after initial fear conditioning was also unchanged in CBPAHAT ${ }^{\mathrm{PFC}}$ and mCREB $^{\mathrm{PFC}}$ mice. In addition, there was no difference between tested groups in responses to CS+ across the entire contextual or auditory discriminatory tasks. The abnormal performance of mutant mice in contextual and auditory discriminatory tasks was specific to deficits in responsiveness to CS - only and during later phases of the tasks. These data suggest that the prefrontal circuit is critically involved in learning appropriate responses to nonrelevant stimuli that are similar yet not identical to aversive stimuli. These data are consistent with the previously described function of the PFC in fear memory extinction. Increasing evidence from human (Kesner and Rogers 2004; Blumenfeld and Ranganath 2007) and animal (Hirsch and Crepel 1992; Morris et al. 1999; Takita et al. 1999; Quirk et al. 2000; Izaki et al. 2002; Maroun and Richter-Levin 2003; Santini et al. 2004; Kawashima et al. 2006; Richter-Levin and Maroun 2010) studies implicate the PFC in extinction of conditioned fear (Sotres-Bayon et al. 2006; Quirk and Mueller 2008) and conditioned taste aversion (Akirav et al. 2006).

\section{A}
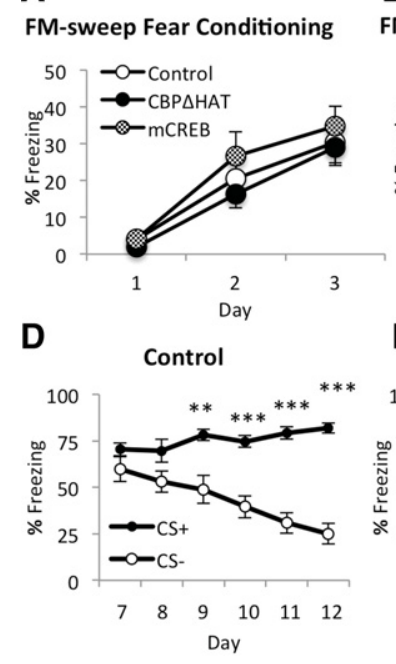

\section{G} Discrimination Index
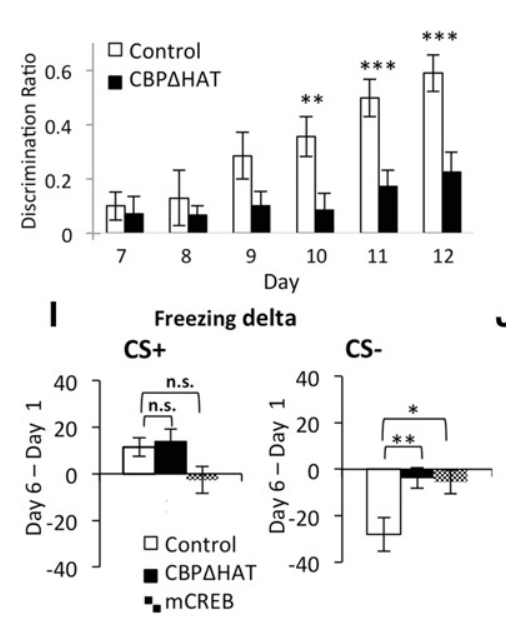

$\mathrm{E}$
C Generalization Test
$100 \quad$ aCS+ $\square$ CS$\underbrace{100}_{\text {Control CBPSHAT mCREB }}$

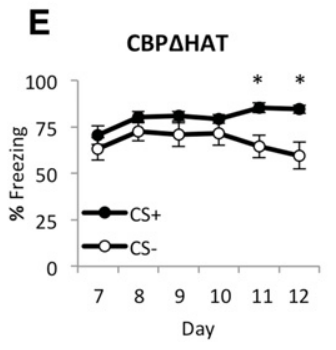

F mCREB

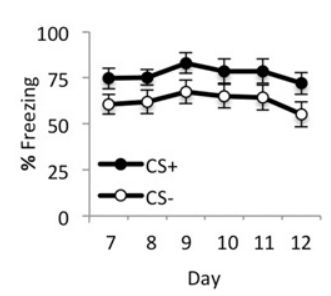

H Discrimination Index

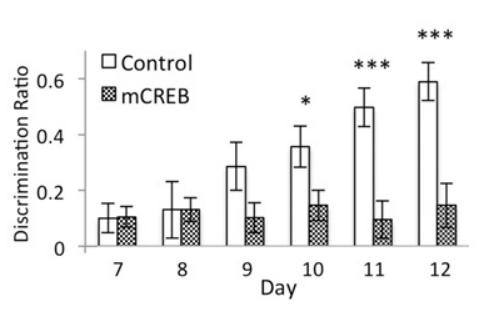

J Average learning curves

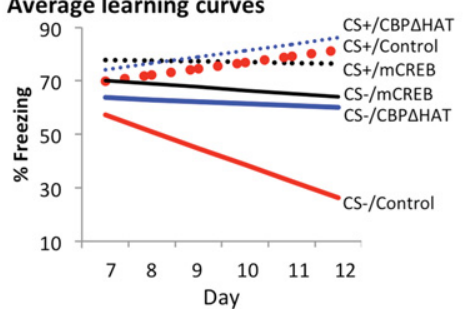

Figure 4. (Legend on next page) 
There is converging evidence that links fear memory specificity and generality with information processing in the hippocampus-thalamus-PFC-amygdala circuit (Marr 1971; O'Reilly and McClelland 1994; Leutgeb et al. 2007; McHugh et al. 2007; Kumaran and McClelland 2012; Nakashiba et al. 2012; Xu et al. 2012; Navawongse and Eichenbaum 2013; Xu and Sudhof 2013). Involvement of the PFC in context or odor discrimination during information acquisition has been previously studied (DeVito et al. 2010; Xu et al. 2012; Xu and Sudhof 2013); however, the contribution of the PFC in the discrimination of auditory patterns, such as FM-sweep direction, has not been previously explored. FM-sweep direction discrimination is important in speech recognition (Zeng et al. 2005) but its underlying neural mechanism is unknown. Auditory fear conditioning has been extensively studied and depends on synaptic plasticity within the amygdala (Fanselow and LeDoux 1999; LeDoux 2000) but neural substrates for auditory fear discrimination are less well studied in mice. Recently, it was suggested that stimulus convergence in the auditory cortex is necessary for the associative fear learning of frequency-modulated sweeps (Letzkus et al. 2011). A reduced reliance on FM-sweep direction stimuli in $\mathrm{CBP} \Delta \mathrm{HAT}^{\mathrm{PFC}}$ and mCREB $^{\text {PFC }}$ mice indicates that the mPFC supports directly auditory fear memory specificity.

There is a general difference in the patterns of freezing responses to CS+/CS - between auditory and context discrimination in control animals. While the direction of learning curves (upward/downward) remains the same, their steepness varies. In the context discrimination assay (Fig. 1J), the learning of appropriate responses to CS+ showed a significantly positive slope
(CS+/Control, $\alpha=4.76 \pm 1.07$, where $\alpha=$ slope) (Fig. 1J), while the learning of the appropriate response to CS - showed a slight negative slope (CS $-/$ Control, $\alpha=-0.88 \pm 1.34$ ) (Fig. 1J). The marked improvement of discrimination observed on the FM-sweep direction fear discriminatory task in control mice (Fig. 4D) coincides with the slight positive slope of the learning curve for $\mathrm{CS}+(\mathrm{CS}+/$ Control, $\alpha=2.366 \pm 0.82)$ (Fig. 1J) and the significant negative slope of the learning curve for CS - (CS - / Control, $\alpha=-6.176 \pm 1.22$ ) (Fig. 1J). Two possible factors may have an effect on the steepness of learning curves for acquired responses to $\mathrm{CS}+/ \mathrm{CS}-$ in these discriminatory tasks. First, it is possible that a "floor" effect on CS - curve in the contextual discriminatory task and a "ceiling" effect on CS + curve in the auditory discriminatory task may account for these differences. The initial level of freezing is substantially lower in the contextual discriminatory task ( $\sim 25 \%$ of initial freezing) (Fig. 1F,G) when compared to the auditory discrimination task $(>75 \%$ of initial freezing) (Fig. 4D-F). Second, it may be more difficult to extinguish responses to nonrelevant stimuli (Context B) because of the high complexity of contextual stimuli (multimodality, more details). Conversely, the rapid decline of responses to downsweep (CS -) may result from the lower complexity (single modality) of the auditory stimuli and, subsequently, more effective discrimination training.

Recently, it has been proposed that disruption of the PFC circuit during information acquisition may result in overgenerality. Inactivation of prefrontal inputs to the nucleus reuniens resulted in an increased fear generalization to novel contextual stimuli (Xu et al. 2012). Our manipulation of the mPFC differed and targeted CBP-dependent nuclear processes, which may not produce immediate global effects on firing properties of the mPFC neurons during information acquisition, but rather have effects on the properties of the neural circuits relevant to long-term memory consolidation. However, it is unclear whether the abnormality in fear memory accuracy found in CBPAHAT ${ }^{\mathrm{PFC}}$ mice resulted from fear driven overgeneralization or a deficit to access memory details (i.e., memory resolution).

The difficulties with studying CBP function in cognition are confounded by the high complexity of the CBP protein, which can integrate or antagonize multiple signaling pathways, and by its distinctive roles in developing and mature circuits. Haploid insufficiency mutations in CBP (Chrivia et al. 1993) or its homolog p300 (Eckner et al. 1994) result in Rubinstein-Taybi syndrome (RTS) (Rubinstein and Taybi 1963; Petrij et al. 1995), which is a developmental disorder characterized by severe mental retardation. CBP and p300 both share a very similar molecular structure (Arany et al. 1994), including intrinsic acetyltransferase activity (Ogryzko et al. 1996), and are capable to mediate similar cellular functions including CREB-dependent transcriptional activation. The functional differences between these two redundant genes are due to their highly overlapping but different patterns of expression and not yet understood 
functional specificity. Prenatal lethality in CBP knockout mice demonstrates an essential role of this gene in embryogenesis (Yao et al. 1998). CBP hemizygote or CBP mutations targeted to excitatory forebrain neurons using CamKII $\alpha$ promoter driven expression, such as conditional knockout or transgenic mice expressing dominant negative variants, display specific deficits in long-term memory but not in short-term memory suggesting that CBP function may support long-term memory encoding. However, these results are not consistent across all CBP mutant strains. In one study, CamKII $\alpha$-dependent conditional knockout of CBP targeted to excitatory neurons during postnatal brain development resulted in deficient short-term memory (Chen et al. 2010). Although CamKII $\alpha$ gene product levels are low during early phases of brain development, a large increase in the expression is usually observed between postnatal days 10 to 30 (Sugiura and Yamauchi 1992; Kojima et al. 1997) coinciding with postnatal brain development. Since the developmental time of CBP conditional deletion was not reported in this study, one cannot eliminate developmental confounds underlying the behavioral phenotype. Thus, it is difficult to dissociate between developmental defects, developmental compensatory effects, and acute deficits in mutant mice with CBP hypofunction during critical periods of postnatal brain development. However, when manipulation of CBP activity is performed in the adult brain, data consistently implicate CBP acetyltransferase function in neural epigenetic signaling underlying long-term synaptic plasticity and long-term memory consolidation (Korzus et al. 2004; Barrett et al. 2011; Maddox et al. 2013). In addition, testing of CamKII $\alpha$ positive cell-restricted and adult mice induced CBP knockout mice indicated that environment-induced adult neurogenesis is extrinsically regulated by CBP function in mature hippocampal granule cells (Lopez-Atalaya et al. 2011). Considering that adult neurogenesis in the hippocampus constitutes an adaptive mechanism to optimally encode contextual information important for memory resolution (Aimone et al. 2011; Sahay et al. 2011) and CBP mutant demonstrates deficiency in spatial discrimination (Lopez-Atalaya et al. 2011) it is likely that CBP is also involved in adult neurogenesis-dependent long-term encoding of contextual information. However, in CBP $\triangle \mathrm{HAT}^{\mathrm{PFC}}$ or $\mathrm{mCREB}^{\mathrm{PFC}}$ mice hypofunction was targeted to the mPFC and it is unlikely that this manipulation would have an effect on adult neurogenesis in the hippocampus.

How can CBP enzymatic activity regulate neural function? The regulation of gene expression requires not only an activation of transcription factors but also the recruitment of multifunctional coactivators that are independently regulated and directly involved in the chromatin remodeling underlying epigenetic regulatory mechanisms (Rosenfeld and Glass 2001). For example, recent work demonstrated the importance of chromatin remodeling factors like the SWI/SNF complex in neuronal function underlying memory (Vogel-Ciernia et al. 2013). While CBP's function as a platform to recruit other required coactivators appears to be indispensable for CREB-dependent transcription, the recruitment for lysine acetyltransferase activity is transcription unit specific and may depend on the structure of chromatin at a specific locus and/or a specific cell type (Puri et al. 1997; Korzus et al. 1998). Changes in histone acetylation are predictive for gene expression (Allfrey et al. 1964; Pogo et al. 1966). The concordance between the histone acetylation and transcription levels increases over time and the positive correlation between both has been confirmed in genome-wide studies (Kurdistani and Grunstein 2003; Karlic et al. 2010; Markowetz et al. 2010). It is important to emphasize that these are correlations only and that causal relationships between histone modification and gene expression in the brain in vivo will require additional investigation. In addition, a number of nonhistone proteins have been identified as substrates for CBP (Kouzarides 2000; Sterner and Berger 2000; Yang 2004; Glozak et al. 2005; Kimura et al. 2005) including CREB (Lu et al. 2003). Regardless of the uncertainty of the CBP's acetyltransferase critical target(s), genetic and pharmacological studies have indicated that hypofunction of CBP's acetyltransferase activity interferes with mechanisms that support memory consolidation and reconsolidation in brain neural networks (Korzus et al. 2004; Maddox et al. 2013). Current data indicate that the acquisition fear memory accuracy involves CBP-dependent mechanism within mPFC circuitry.

Thus, locomotor activity, anxiety-related responses, and fear conditioning were normal in CBP $\Delta \mathrm{HAT}^{\mathrm{PFC}}$ mice, yet these mutant mice showed a strong deficit in fear memory accuracy in both contextual and auditory discrimination assays. Both context and auditory fear discrimination tasks required temporal integration because the animals learned subtle differences between relevant and nonrelevant stimuli over many days with a single exposure to both CS + and CS - per day. Inhibition of a component of neural signaling immediately upstream of CBP by a direct blockade of CREB ability to recruit CBP to the target promoter in the mPFC produced identical effects as CBP $\Delta$ HAT on the capability of mice to learn the distinction between auditory stimuli. Thus, impairment of either component of CREB/CBP-dependent signaling (CREB phosphorylation or CBP's acetyltransferase activity) within the mPFC circuitry resulted in a deficit in auditory fear memory specificity indicating that the MPFC circuitry supports the disambiguation of auditory fear signals.

How CBP and CREB control memory accuracy in the MPFC is unclear. Both CBP and especially CREB have been implicated in long-term plasticity and memory consolidation in Aplysia, Drosophila, and mice. Thus it is possible that long-term coding within mPFC network involving LTP-mediated modification of prefrontal circuits is critical during contextual and auditory fear discrimination. This type of plasticity in the MPFC might be required to extinguish CS - responses, which would be consistent with the recognized role of the mPFC in fear memory extinction. In addition, CREB has been strongly implicated in adaptive alteration of neuronal excitability and memory allocation (Rogerson et al. 2014) and it is possible that CBP may mediate CREB-dependent changes in neuronal excitability.

There is converging evidence that links contextual fear memory specificity and generality with information processing in the hippocampus-thalamus-PFC-amygdala circuit (Marr 1971; O'Reilly and McClelland 1994; Leutgeb et al. 2007; McHugh et al. 2007; Kumaran and McClelland 2012; Nakashiba et al. 2012; Xu et al. 2012; Navawongse and Eichenbaum 2013; Xu and Sudhof 2013). Our findings are consistent with the conclusions reported by DeVito et al. (2010), who suggested that the $\mathrm{mPFC}$ circuit was critical for the acquisition of overlapping odor discrimination problems. Thus, the present findings of the critical role of the mPFC in auditory and context discrimination provide further evidence for the high integration-dependent disambiguation function of the mPFC because similar contexts (or up/down FM-sweeps) were both presented during multiple day training consisting of discontiguous episodes before the animals acquired the ability to properly respond to these signals. These data indicate that certain types of prefrontal dysfunction are likely to contribute to overgeneralized fear, a clinical condition present in anxiety related disorders such as PTSD.

\section{Materials and Methods}

\section{Subjects}

C57BL/6J mice were used for all experiments. Prior to any procedure, the mice are weaned at postnatal day 21 , housed four 
animals to a cage with same-sex littermates, maintained on a 12-h light-dark cycle, and had ad libitum access to food and water. Autoclaved bedding was changed every week. All procedures were approved by the UC Riverside Institutional Animal Care and Use Committee in accordance with the NIH guidelines for the care and use of laboratory mice.

\section{Surgery}

The injection protocol has been previously described by Cetin et al. (2006). In this study, 2- to 4-mo-old mice were individually housed and weighed to determine the appropriate drug ratios to use. Atropine was injected to help with breathing $(0.02 \mathrm{mg} / \mathrm{kg}$ body weight). The mice were then placed into an isoflurane chamber to induce anesthesia, mounted in a heated stereotaxic apparatus, and supplied with a constant flow of isoflurane/oxygen mix. The scalp was shaved and sanitized with 70\% ethanol. The ear bars, bite bar, and nose clamp were adjusted to firmly hold the head in place. A midline incision was made on the scalp, and surgical hooks were placed to keep the skull exposed. Sterile PBS was added as needed to prevent the skull from drying. The head was leveled by comparing bregma and lambda coordinates until they were equivalent. Injection sites were calculated based on bregma coordinates, and a dental drill was used to thin the skull over the injection site. A $27 \mathrm{G}$ needle was then used to remove the thinned bone. A 5- $\mu \mathrm{L}$ calibrated glass micropipette (8-mm taper, $8-\mu \mathrm{m}$ internal tip diameter) was fitted with a plastic tube connected to a 10-mL syringe and lowered onto a square of Parafilm containing a $4-\mu \mathrm{L}$ drop of virus. The syringe was aspirated to fill the micropipette with solution before moving it to the injection site. The micropipette was slowly lowered to the proper stereotaxic coordinates and pressure was applied to the syringe to inject $1 \mu \mathrm{L}$ of solution at a rate of $50 \mathrm{~nL} / \mathrm{min}$. After the total volume was injected, the micropipette was withdrawn slowly to avoid backflow, and the injection site was cleaned with sterile cotton swabs. The skin was sutured, and antibiotic was applied to the scalp. Lidocaine was subcutaneously injected near the site followed by an intraperitoneal injection of sterile PBS $(30 \mathrm{~mL} / \mathrm{kg}$ body weight $)$ to prevent dehydration. The mouse was kept warm by placing its cage on a heated plate and injected with buprenorphine $(0.05 \mathrm{mg} /$ $\mathrm{kg}$ ) for pain relief. On post-surgical Days 1 and 2, the mouse received subcutaneous injections of meloxicam $(1 \mathrm{mg} / \mathrm{kg})$ to relieve pain. Animals were monitored for any signs of distress or inflammation for $3 \mathrm{~d}$ after surgery. Behavioral experiments were initiated $3 \mathrm{~d}$ after surgery. The infralimbic and prelimbic cortices were targeted at the following stereotaxic coordinates: bregma, AP 1.8, $\mathrm{ML} \pm 0.4$, DV 1.4.

\section{Viruses}

Surgical procedures were standardized to minimize the variability of HSV virus injections, using the same stereotaxic coordinates for the mPFC and the same amount of HSV injected into the mPFC for all mice. CBP $\triangle$ HAT or mCREB and/or EGFP were cloned into the HSV amplicon and packaged using a replication-defective helper virus as previously described (Lim and Neve 2001; Neve and Lim 2001). The viruses (HSV/CMV-CBPAHAT-IRES2-EGFP, HSV/CMV-EGFP, and HSV/mCREB-EGFP) were prepared by Dr. Rachael Neve (MIT, Viral Core Facility). The average titer of the recombinant virus stocks was typically $4.0 \times 10^{7}$ infectious units/ $\mathrm{mL}$. HSV viruses are effectively expressed in neurons in the PFC. The CBP $\triangle$ HAT mutant, a dominant-negative inhibitor of CBPdependent histone acetylation, harbors a substitution mutation of two conserved residues ( $\mathrm{Tyr}^{1540} / \mathrm{Phe}^{1541}$ to $\mathrm{Ala}^{1540} / \mathrm{Ala}^{1541}$ ) in the acetyl CoA binding domain (Korzus et al. 1998). It has been also demonstrated that CBP $\triangle$ HAT lacks histone acetyltransferase activity (Korzus et al. 2004) and blocks c-fos expression in neurons (Korzus et al. 2004). The dominant negative CREB mutant (mCREB) carries substitution mutation Ser $^{133}$ to Ala ${ }^{133}$. Previous studies indicate that mCREB decreased CREB function and blocked neuronal CREB dependent gene expression (Gonzalez et al. 1989; Chrivia et al. 1993; Barrot et al. 2002; Olson et al. 2005).

\section{Behavioral assays}

All behavioral experiments were performed under blind conditions.

\section{Fear conditioning}

Fear conditioning was performed as previously described (Korzus et al. 2004). Fear conditioning training was performed in the fear conditioning box from Coulburn Instruments Inc. After being handled, individual mice were exposed to context A. Context A was the unmodified fear conditioning box, which was placed inside a sound attenuated chamber with the house light and house fan turned on. Performance was scored by measuring freezing behavior, the complete absence of movement (Fanselow 1980). Freezing was scored and analyzed automatically by a Video-based system (Freeze Frame software ActiMetrics Inc.). Video was recorded at 30 frames/sec. The Freeze Frame software calculated a difference between consecutive frames by comparing gray scale value for each pixel in frame. Freezing was defined based on experimenter observations and set as subthreshold activity for longer than 1 sec. Freezing was expressed as a \% Freezing, which was calculated as a percent of freezing time per total time spent in the testing chamber. The chamber was cleaned in between trials with Quatricide, 70\% ethanol, and distilled water.

Contextual fear conditioning. Mice were trained in a standard fear conditioning chamber (Coulburn Instruments Inc.). The individual mice were exposed to context A for $180 \mathrm{sec}$ and received a $0.75-\mathrm{mA}, 2$-sec foot shock (context A-foot shock pairing). The animals were then left for another $180 \mathrm{sec}$ inside the chamber. For the memory retention test, the mice were placed back into the training chamber for $180 \mathrm{sec}$. Freezing was scored and analyzed automatically as described above.

Cued fear conditioning. Mice were trained in a standard fear conditioning chamber (Coulburn Instruments Inc.). After a 3 -min baseline period, one, two, or three 20 -sec tones $(2800 \mathrm{~Hz}$, $75 \mathrm{~dB})$ were played and a shock $(0.75 \mathrm{~mA}, 2 \mathrm{sec})$ was delivered during the final $2 \mathrm{sec}$ of the tone. Twenty-four hours later, mice were placed in a novel enclosure and, after a 3-min baseline exposure, a series of three tones identical to that given in the training session was played. Freezing was scored and analyzed automatically as described above.

Context discrimination. The context discrimination assay was preformed similarly as previously described (Lovelace et al. 2014). After being handled, individual mice were exposed to context A $1 \mathrm{~d}$ before training. The protocol included $14 \mathrm{~d}$ of training, which was divided into three phases: initial training phase, generalization test, and discrimination phase (Fig. 1D). During the initial training phase (Day 1), mice were placed in the context A for 180 sec followed by a single foot shock (arrow) and left for another $60 \mathrm{sec}$ inside the chamber. Context A (CS+) was the unmodified fear conditioning box (Coulburn Instruments Inc.), which was placed inside a sound attenuated chamber with the house light and house fan on. The chamber was cleaned with Quatricide, 70\% ethanol, and distilled water. For generalization test and during discrimination phase, the individual mice were exposed to Context A for $180 \mathrm{sec}$ and received a $0.75-\mathrm{mA}$, 2 -sec foot shock, and left for another $60 \mathrm{sec}$ inside the chamber. Four hours later, the mice were exposed to the similar Context B (CS -) for $242 \mathrm{sec}$ and received no foot shock. Context A and B were similar but not the same. Context B was the modified fear conditioning chamber, with angular wall inserts, house fan off, and scented with Simple Green. Thus animals were exposed to CS +13 times before the final test. The order of exposure to different contexts was counter balanced. Additionally, the context cues themselves were counter balanced within each group in order to isolate the effect of the CS+.

Auditory discrimination. The auditory discrimination task is divided into three phases: initial training phase, generalization test, and 
discrimination phase (Fig. 3). The conditioned stimuli (CS) for auditory fear conditioning were 20 -sec trains of frequency modulated (FM)-sweeps for a 400-msec duration, logarithmically modulated between 2 and $13 \mathrm{kHz}$ (upsweep) or 13 and $2 \mathrm{kHz}$ (downsweep) delivered at $1 \mathrm{~Hz}$ at $75 \mathrm{~dB}$. After habituation, the $\mathrm{CS}+$ was paired with a foot shock $(2 \mathrm{sec}, 0.75 \mathrm{~mA})$. The onset of the US coincided with the onset of the last sweep for the CS. For fear conditioning acquisition (Days 1-3; initial training phase), the animals were presented with a single US-CS pairing per day. The FM-sweep Fear Retrieval (Day 4) and Generalization (Days $4-5$ ) were tested (freezing to $3 \times \mathrm{CS}-$ for $30 \mathrm{sec}$ followed by $3 \times 30$-sec CS + without US; 3-min baseline and 3-min ITI) in context $\mathrm{C}$, which significantly differed from the training chamber (context A). The discrimination phase of FM-sweep direction discrimination training was performed over three sessions a day for $6 \mathrm{~d}$ (Days 7-12): Session 1 was the performance test, Session 2 was the presentation to $1 \times \mathrm{UC}-\mathrm{CS}+$ pairing after a 3 -min baseline, and Session 3 was the presentation to the USCS - pairing after a 3-min baseline. The CS + and CS - were counterbalanced such that half of the CS + group was upsweep and the other half of CS+ was downsweep.

Open-field test. A $17^{\prime \prime} \times 17^{\prime \prime} \times 12^{\prime \prime}$ clear Plexiglas arena with a white acrylic floor was used for the open-field test. The arena was placed in a sound attenuated chamber with a ceiling mounted camera and a dim light. After sanitizing the arena with Quatricide, $70 \% \mathrm{EtOH}$, and distilled water, the mice were individually placed inside the chamber and allowed to explore for $15 \mathrm{~min}$ before being returned to their home cage. Videos are analyzed offline using behavioral analysis software (CleverSys, Inc.) to quantify the level of anxiety and locomotion.

\section{Histology}

Mice were anesthetized using Nembutal $(200 \mathrm{mg} / \mathrm{kg}$, i.p. injection) and transcardially perfused first with PBS and then $4 \%$ PFA. The extracted brain was soaked in 4\% PFA overnight and then transferred to PBS until histological sectioning. In this study, $100-\mu \mathrm{m}$-thick sections of the mPFC were obtained using a Compresstome VF-300 (Precisionary Instr.) and placed in a 24-well plate for free-floating immunohistochemistry (IHC) according to a previously described protocol (Korzus et al. 2004). The sections are washed three times for $10 \mathrm{~min}$ in a wash buffer (PBS, $0.3 \%$ Triton $\mathrm{X}-100,0.02 \% \mathrm{NaN}_{2}$ ) followed by a 1 -h incubation in blocking buffer ( $5 \%$ normal goat serum in washing buffer), followed by a 10-min incubation in the wash buffer. The sections were incubated overnight at $4 \mathrm{C}^{\circ}$ with primary antibodies: anti-NeuN (Millipore, 1:2000), chicken anti-GFP (Molecular Probes, 1:1000), anti-acetyl-Histone H3 (Millipore, 1:2000), or anti-acetyl-Histone H4 (Millipore, 1:2000). After three washes with the wash buffer, the sections were incubated with secondary antibodies (Alexa647-goat anti-mouse IgG, Alexa488-goat antichicken IgG, Alexa647-goat anti-rabbit IgG; Molecular Probes, 1:1000), in blocking buffer for $4 \mathrm{~h}$ at room temperature. The sections were washed again three times with the wash buffer before mounting for viewing. Negative control slices were performed for each row of the well plate, undergoing the same IHC procedure in addition to receiving primary antibodies. After immunostaining, the tissue was mounted directly onto glass slides, covered, and sealed with nail polish before imaging.

\section{Imaging}

The slides were placed on the stage of an Olympus FV1000 laser scanning confocal microscope controlled using the FluoView software. GFP and Alexa-647 were imaged using 473-nm and $647-\mathrm{nm}$ lasers, respectively. The background fluorescence was measured and subtracted for each image. The fluorescence intensity was compared to the negative control slices, which did not receive any primary antibodies. Immunostained tissue was analyzed using a semiautomatic laser scanning confocal microscope (Olympus FV1000) controlled by the FluoView software. Multiple brain sections were imaged using identical microscope settings. Eighty-micrometer z-stacks were obtained from the PL region in the mPFC, and region of interest (ROI) analysis was used for quantification. The background fluorescence was measured for each image and then subtracted. The intensity quantification was performed using the FluoView Olympus software and NIH Image J.

\section{Histone acetylation assay}

Individual mice were trained on a fear conditioning paradigm in which they were presented with a 20 -sec auditory stimulus followed immediately by a 2 -sec foot shock (0.75-mA intensity). The auditory stimulus is the same as used for behavioral training in which logarithmically modulated upward $(2-13 \mathrm{kHz})$ frequency-modulated sweeps are presented in $400-$ msec bouts at a $1-\mathrm{Hz}$ frequency for a total duration of $20 \mathrm{sec}$. Three minutes after the foot shock, mice were placed in their home cage for 25 min undisturbed. Immunohistology and imaging were performed as described above. The region of interest (ROI) was a $5-\mu \mathrm{m}$ circle placed on cells expressing GFP within cortical layer $2 / 3$ in mPFC and fluorescence corresponding to acetylated histone $\mathrm{H} 3$ or $\mathrm{H} 4$ was measured from randomly selected 50-60 cells per hemisphere. The fluorescence intensity quantification was performed on original images by the use of Olympus Fluoview software.

\section{Data analysis}

The experimenters were blind to the group conditions. Data are expressed as the means \pm SEM. $N$ indicates number of animals unless stated otherwise. Statistical analysis was performed using Excel (Microsoft Inc.) or SPSS (IBM Inc.). The Student's $t$-test or ANOVA was used for statistical comparisons. Pearson's correlation $(r)$ was used as an effect size. In cases where the repeated measures ANOVA (RM-ANOVA) was utilized and assumptions of sphericity were violated (via Mauchly's Test), the analysis was performed using the Greenhouse-Geisser correction. Where applicable, post hoc analysis with Bonferroni correction was performed for multiple comparisons, which allows for substantially conservative control of the error rate. A $P<0.05$ was considered statistically significant. The asterisks indicate statistical significance: $\left(^{*}\right) P<0.05$, ${ }^{(*)} P<0.01,(* * *) P<0.001$, (n.s.) not significant.

\section{Acknowledgments}

This work was supported by the National Institutes of Health/ National Institute of Mental Health grant MH086078 (to E.K.), a Ford Fellowship (to P.A.V.), and the Canadian Institutes of Health Research grant MOP-74650 (to S.A.J.). We thank A. Bana, A. Hiroto, and C.L. Hughes for their technical assistance.

\section{References}

Aimone JB, Deng W, Gage FH. 2011. Resolving new memories: a critical look at the dentate gyrus, adult neurogenesis, and pattern separation. Neuron 70: $589-596$.

Akirav I, Khatsrinov V, Vouimba RM, Merhav M, Ferreira G, Rosenblum K, Maroun M. 2006. Extinction of conditioned taste aversion depends on functional protein synthesis but not on NMDA receptor activation in the ventromedial prefrontal cortex. Learn Mem 13: 254-258.

Alarcon JM, Malleret G, Touzani K, Vronskaya S, Ishii S, Kandel ER, Barco A. 2004. Chromatin acetylation, memory, and LTP are impaired in $\mathrm{CBP}+/-$ mice: a model for the cognitive deficit in Rubinstein-Taybi syndrome and its amelioration. Neuron 42: 947-959.

Allfrey VG, Faulkner R, Mirsky AE. 1964. Acetylation and methylation of histones and their possible role in the regulation of RNA synthesis. Proc Natl Acad Sci 51: 786-794.

Arany Z, Sellers WR, Livingston DM, Eckner R. 1994. E1A-associated p300 and CREB-associated CBP belong to a conserved family of coactivators. Cell 77: 799-800.

Bannister AJ, Kouzarides T. 1996. The CBP co-activator is a histone acetyltransferase. Nature 384: 641-643.

Barrett RM, Malvaez M, Kramar E, Matheos DP, Arrizon A, Cabrera SM, Lynch G, Greene RW, Wood MA. 2011. Hippocampal focal knockout of CBP affects specific histone modifications, long-term potentiation, and long-term memory. Neuropsychopharmacology 36: 1545-1556. 
Barrot M, Olivier JD, Perrotti LI, DiLeone RJ, Berton O, Eisch AJ, Impey S, Storm DR, Neve RL, Yin JC, et al. 2002. CREB activity in the nucleus accumbens shell controls gating of behavioral responses to emotional stimuli. Proc Natl Acad Sci 99: 11435-11440.

Blumenfeld RS, Ranganath C. 2007. Prefrontal cortex and long-term memory encoding: an integrative review of findings from neuropsychology and neuroimaging. Neuroscientist 13: 280-291.

Bourtchuladze R, Frenguelli B, Blendy J, Cioffi D, Schutz G, Silva AJ. 1994 Deficient long-term memory in mice with a targeted mutation of the cAMP-responsive element-binding protein. Cell 79: 59-68.

Cetin A, Komai S, Eliava M, Seeburg PH, Osten P. 2006. Stereotaxic gene delivery in the rodent brain. Nat Protoc 1: 3166-3173.

Chen G, Zou X, Watanabe H, van Deursen JM, Shen J. 2010. CREB binding protein is required for both short-term and long-term memory formation. J Neurosci 30: 13066-13077.

Chrivia JC, Kwok RP, Lamb N, Hagiwara M, Montminy MR, Goodman RH. 1993. Phosphorylated CREB binds specifically to the nuclear protein CBP. Nature 365: 855-859.

Dash PK, Hochner B, Kandel ER. 1990. Injection of the cAMP-responsive element into the nucleus of Aplysia sensory neurons blocks long-term facilitation. Nature 345: 718-721.

DeVito LM, Lykken C, Kanter BR, Eichenbaum H. 2010. Prefrontal cortex: role in acquisition of overlapping associations and transitive inference. Learn Mem 17: 161-167.

Eckner R, Ewen ME, Newsome D, Gerdes M, DeCaprio JA, Lawrence JB, Livingston DM. 1994. Molecular cloning and functional analysis of the adenovirus E1A-associated 300-kD protein ( $\mathrm{p} 300$ ) reveals a protein with properties of a transcriptional adaptor. Genes Dev 8: 869-884.

Fanselow MS. 1980. Conditioned and unconditional components of post-shock freezing. Pavlov J Biol Sci 15: 177-182.

Fanselow MS, LeDoux JE. 1999. Why we think plasticity underlying Pavlovian fear conditioning occurs in the basolateral amygdala. Neuron 23: $229-232$.

Glozak MA, Sengupta N, Zhang X, Seto E. 2005. Acetylation and deacetylation of non-histone proteins. Gene 363: 15-23.

Gonzalez GA, Yamamoto KK, Fischer WH, Karr D, Menzel P, Biggs W III, Vale WW, Montminy MR. 1989. A cluster of phosphorylation sites on the cyclic AMP-regulated nuclear factor CREB predicted by its sequence. Nature 337: 749-752.

Gu W, Roeder RG. 1997. Activation of p53 sequence-specific DNA binding by acetylation of the p53 C-terminal domain. Cell 90: $595-606$.

Guan Z, Giustetto M, Lomvardas S, Kim JH, Miniaci MC, Schwartz JH, Thanos D, Kandel ER. 2002. Integration of long-term-memory-related synaptic plasticity involves bidirectional regulation of gene expression and chromatin structure. Cell 111: 483-493.

Hirsch JC, Crepel F. 1992. Postsynaptic calcium is necessary for the induction of LTP and LTD of monosynaptic EPSPs in prefrontal neurons: an in vitro study in the rat. Synapse 10: 173-175.

Izaki Y, Takita M, Nomura M. 2002. Local properties of CA1 region in hippocampo-prefrontal synaptic plasticity in rats. Neuroreport 13: 469-472.

Josselyn SA, Shi C, Carlezon WA Jr, Neve RL, Nestler EJ, Davis M. 2001. Long-term memory is facilitated by cAMP response element-binding protein overexpression in the amygdala. J Neurosci 21: 2404-2412.

Karlic R, Chung HR, Lasserre J, Vlahovicek K, Vingron M. 2010. Histone modification levels are predictive for gene expression. Proc Natl Acad Sci 107: 2926-2931.

Kawashima H, Izaki Y, Grace AA, Takita M. 2006. Cooperativity between hippocampal-prefrontal short-term plasticity through associative long-term potentiation. Brain Res 1109: 37-44.

Kesner RP, Rogers J. 2004. An analysis of independence and interactions of brain substrates that subserve multiple attributes, memory systems, and underlying processes. Neurobiol Learn Mem 82: 199-215.

Kida S, Josselyn SA, de Ortiz SP, Kogan JH, Chevere I, Masushige S, Silva AJ. 2002. CREB required for the stability of new and reactivated fear memories. Nat Neurosci 5: 348-355.

Kimura A, Matsubara K, Horikoshi M. 2005. A decade of histone acetylation: marking eukaryotic chromosomes with specific codes. J Biochem 138: 647-662.

Kojima N, Wang J, Mansuy IM, Grant SG, Mayford M, Kandel ER. 1997. Rescuing impairment of long-term potentiation in fyn-deficient mice by introducing Fyn transgene. Proc Natl Acad Sci 94: 4761-4765.

Korzus E, Torchia J, Rose DW, Xu L, Kurokawa R, McInerney EM, Mullen TM, Glass CK, Rosenfeld MG. 1998. Transcription factor-specific requirements for coactivators and their acetyltransferase functions. Science 279: 703-707.

Korzus E, Rosenfeld MG, Mayford M. 2004. CBP histone acetyltransferase activity is a critical component of memory consolidation. Neuron 42: 961-972.

Kouzarides T. 2000. Acetylation: a regulatory modification to rival phosphorylation? EMBO J 19: 1176-1179.
Kumaran D, McClelland JL. 2012. Generalization through the recurrent interaction of episodic memories: a model of the hippocampal system. Psychol Rev 119: 573-616.

Kurdistani SK, Grunstein M. 2003. Histone acetylation and deacetylation in yeast. Nat Rev Mol Cell Biol 4: 276-284.

LeDoux JE. 2000. Emotion circuits in the brain. Annu Rev Neurosci 23: $155-184$.

Letzkus JJ, Wolff SB, Meyer EM, Tovote P, Courtin J, Herry C, Luthi A. 2011. A disinhibitory microcircuit for associative fear learning in the auditory cortex. Nature 480: 331-335.

Leutgeb JK, Leutgeb S, Moser MB, Moser EI. 2007. Pattern separation in the dentate gyrus and CA3 of the hippocampus. Science 315: 961-966.

Lim F, Neve RL. 2001. Generation of high-titer defective HSV-1 vectors. Curr Protoc Neurosci Chapter 4: Unit 413.

Lopez-Atalaya JP, Ciccarelli A, Viosca J, Valor LM, Jimenez-Minchan M, Canals S, Giustetto M, Barco A. 2011. CBP is required for environmental enrichment-induced neurogenesis and cognitive enhancement. EMBO J 30: 4287-4298.

Lovelace JW, Vieira PA, Corches A, Mackie K, Korzus E. 2014. Impaired fear memory specificity associated with deficient endocannabinoiddependent long-term plasticity. Neuropsychopharmacology 39: $1685-1693$

Lu Q, Hutchins AE, Doyle CM, Lundblad JR, Kwok RP. 2003. Acetylation of cAMP-responsive element-binding protein (CREB) by CREB-binding protein enhances CREB-dependent transcription. J Biol Chem 278: $15727-15734$.

Maddox SA, Watts CS, Schafe GE. 2013. p300/CBP histone acetyltransferase activity is required for newly acquired and reactivated fear memories in the lateral amygdala. Learn Mem 20: 109-119.

Mahan AL, Ressler KJ. 2012. Fear conditioning, synaptic plasticity and the amygdala: implications for posttraumatic stress disorder. Trends Neurosci 35: 24-35.

Markowetz F, Mulder KW, Airoldi EM, Lemischka IR, Troyanskaya OG. 2010. Mapping dynamic histone acetylation patterns to gene expression in nanog-depleted murine embryonic stem cells. PLoS Comput Biol 6: e1001034.

Maroun M, Richter-Levin G. 2003. Exposure to acute stress blocks the induction of long-term potentiation of the amygdala-prefrontal cortex pathway in vivo. J Neurosci 23: 4406-4409.

Marr D. 1971. Simple memory: a theory for archicortex. Philos Trans $R$ Soc Lond B Biol Sci 262: 23-81.

McHugh TJ, Jones MW, Quinn JJ, Balthasar N, Coppari R, Elmquist JK, Lowell BB, Fanselow MS, Wilson MA, Tonegawa S. 2007. Dentate gyrus NMDA receptors mediate rapid pattern separation in the hippocampal network. Science 317: 94-99.

Morris SH, Knevett S, Lerner EG, Bindman LJ. 1999. Group I mGluR agonist DHPG facilitates the induction of LTP in rat prelimbic cortex in vitro. J Neurophysiol 82: 1927-1933.

Nakashiba T, Cushman JD, Pelkey KA, Renaudineau S, Buhl DL, McHugh TJ, Rodriguez Barrera V, Chittajallu R, Iwamoto KS, McBain CJ, et al. 2012. Young dentate granule cells mediate pattern separation, whereas old granule cells facilitate pattern completion. Cell 149: $188-201$.

Navawongse R, Eichenbaum H. 2013. Distinct pathways for rule-based retrieval and spatial mapping of memory representations in hippocampal neurons. J Neurosci 33: 1002-1013.

Neve RL, Lim F. 2001. Overview of gene delivery into cells using HSV-1-based vectors. Curr Protoc Neurosci Chapter 4: Unit 412.

Ogryzko VV, Schiltz RL, Russanova V, Howard BH, Nakatani Y. 1996. The transcriptional coactivators $\mathrm{p} 300$ and CBP are histone acetyltransferases. Cell 87: 953-959.

Olson VG, Zabetian CP, Bolanos CA, Edwards S, Barrot M, Eisch AJ, Hughes T, Self DW, Neve RL, Nestler EJ. 2005. Regulation of drug reward by cAMP response element-binding protein: evidence for two functionally distinct subregions of the ventral tegmental area. $J$ Neurosci 25: 5553-5562.

O'Reilly RC, McClelland JL. 1994. Hippocampal conjunctive encoding, storage, and recall: avoiding a trade-off. Hippocampus 4: 661-682.

Paxinos G, Franklin KBJ. 2001. The mouse brain in stereotaxic coordinates. Academic Press, San Diego, CA.

Peixoto L, Abel T. 2012. The role of histone acetylation in memory formation and cognitive impairments. Neuropsychopharmacology 38: $62-76$.

Petrij F, Giles RH, Dauwerse HG, Saris JJ, Hennekam RC, Masuno M, Tommerup N, van Ommen GJ, Goodman RH, Peters DJ, et al. 1995. Rubinstein-Taybi syndrome caused by mutations in the transcriptional co-activator CBP. Nature 376: 348-351.

Pittenger C, Huang YY, Paletzki RF, Bourtchouladze R, Scanlin H, Vronskaya S, Kandel ER. 2002. Reversible inhibition of CREB/ATF transcription factors in region CA1 of the dorsal hippocampus disrupts hippocampus-dependent spatial memory. Neuron 34: 447-462. 
Pogo BG, Allfrey VG, Mirsky AE. 1966. RNA synthesis and histone acetylation during the course of gene activation in lymphocytes. Proc Natl Acad Sci 55: 805-812.

Puri PL, Sartorelli V, Yang XJ, Hamamori Y, Ogryzko VV, Howard BH, Kedes L, Wang JY, Graessmann A, Nakatani Y, et al. 1997. Differential roles of $\mathrm{p} 300$ and PCAF acetyltransferases in muscle differentiation. Mol Cell 1: 35-45.

Quirk GJ, Mueller D. 2008. Neural mechanisms of extinction learning and retrieval. Neuropsychopharmacology 33: 56-72.

Quirk GJ, Russo GK, Barron JL, Lebron K. 2000. The role of ventromedial prefrontal cortex in the recovery of extinguished fear. J Neurosci 20: 6225-6231.

Richter-Levin G, Maroun M. 2010. Stress and amygdala suppression of metaplasticity in the medial prefrontal cortex. Cereb Cortex 20: $2433-2441$.

Rogerson T, Cai DJ, Frank A, Sano Y, Shobe J, Lopez-Aranda MF, Silva AJ. 2014. Synaptic tagging during memory allocation. Nat Rev Neurosci 15: $157-169$.

Rosenfeld MG, Glass CK. 2001. Coregulator codes of transcriptional regulation by nuclear receptors. J Biol Chem 276: 36865-36868.

Rubinstein JH, Taybi H. 1963. Broad thumbs and toes and facial abnormalities. A possible mental retardation syndrome. Am J Dis Child 105: $588-608$.

Sahay A, Wilson DA, Hen R. 2011. Pattern separation: a common function for new neurons in hippocampus and olfactory bulb. Neuron 70: $582-588$.

Santini E, Ge H, Ren K, Pena de Ortiz S, Quirk GJ. 2004. Consolidation of fear extinction requires protein synthesis in the medial prefrontal cortex. J Neurosci 24: 5704-5710.

Sotres-Bayon F, Cain CK, LeDoux JE. 2006. Brain mechanisms of fear extinction: historical perspectives on the contribution of prefrontal cortex. Biol Psychiatry 60: 329-336.

Sterner DE, Berger SL. 2000. Acetylation of histones and transcription-related factors. Microbiol Mol Biol Rev 64: 435-459.

Sugiura H, Yamauchi T. 1992. Developmental changes in the levels of $\mathrm{Ca}^{2+} /$ calmodulin-dependent protein kinase II $\alpha$ and $\beta$ proteins in soluble and particulate fractions of the rat brain. Brain Res 593: 97-104

Takita M, Izaki Y, Jay TM, Kaneko H, Suzuki SS. 1999. Induction of stable long-term depression in vivo in the hippocampal-prefrontal cortex pathway. Eur J Neurosci 11: 4145-4148.
Valor LM, Pulopulos MM, Jimenez-Minchan M, Olivares R, Lutz B, Barco A. 2011. Ablation of CBP in forebrain principal neurons causes modest memory and transcriptional defects and a dramatic reduction of histone acetylation but does not affect cell viability. J Neurosci 31: $1652-1663$.

Valor LM, Viosca J, Lopez-Atalaya JP, Barco A. 2013. Lysine acetyltransferases CBP and p300 as therapeutic targets in cognitive and neurodegenerative disorders. Curr Pharm Des 19: 5051-5064.

Vogel-Ciernia A, Matheos DP, Barrett RM, Kramar EA, Azzawi S, Chen Y, Magnan CN, Zeller M, Sylvain A, Haettig J, et al. 2013. The neuron-specific chromatin regulatory subunit BAF53b is necessary for synaptic plasticity and memory. Nat Neurosci 16: $552-561$.

Wood MA, Kaplan MP, Park A, Blanchard EJ, Oliveira AM, Lombardi TL, Abel T. 2005. Transgenic mice expressing a truncated form of CREB-binding protein (CBP) exhibit deficits in hippocampal synaptic plasticity and memory storage. Learn Mem 12: 111-119.

Xu W, Sudhof TC. 2013. A neural circuit for memory specificity and generalization. Science 339: 1290-1295.

Xu W, Morishita W, Buckmaster PS, Pang ZP, Malenka RC, Sudhof TC. 2012. Distinct neuronal coding schemes in memory revealed by selective erasure of fast synchronous synaptic transmission. Neuron 73: 990-1001.

Yang XJ. 2004. Lysine acetylation and the bromodomain: a new partnership for signaling. Bioessays 26: 1076-1087.

Yao TP, Oh SP, Fuchs M, Zhou ND, Ch'ng LE, Newsome D, Bronson RT, Li E, Livingston DM, Eckner R. 1998. Gene dosage-dependent embryonic development and proliferation defects in mice lacking the transcriptional integrator p300. Cell 93: 361-372.

Yin JC, Wallach JS, Del Vecchio M, Wilder EL, Zhou H, Quinn WG, Tully T. 1994. Induction of a dominant negative CREB transgene specifically blocks long-term memory in Drosophila. Cell 79: 49-58.

Zeng FG, Nie K, Stickney GS, Kong YY, Vongphoe M, Bhargave A, Wei C, Cao K. 2005. Speech recognition with amplitude and frequency modulations. Proc Natl Acad Sci 102: 2293-2298.

Received May 19, 2014; accepted in revised form June 11, 2014. 


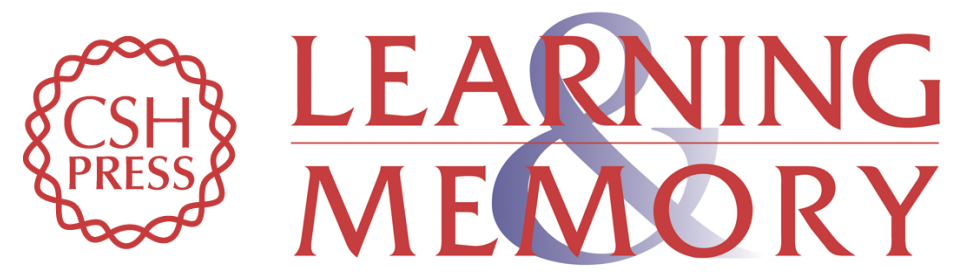

\section{Prefrontal consolidation supports the attainment of fear memory accuracy}

Philip A. Vieira, Jonathan W. Lovelace, Alex Corches, et al.

Learn. Mem. 2014, 21:

Access the most recent version at doi:10.1101/Im.036087.114

\begin{aligned} & \hline References $\begin{array}{l}\text { This article cites } 81 \text { articles, } 28 \text { of which can be accessed free at: } \\ \text { http://learnmem.cshlp.org/content/21/8/394.full.html\#ref-list-1 }\end{array} \\ & \begin{aligned} \text { Creative } \\ \text { Commons } \\ \text { License }\end{aligned} \begin{array}{l}\text { This article is distributed exclusively by Cold Spring Harbor Laboratory Press for the } \\ \text { first } 12 \text { months after the full-issue publication date (see } \\ \text { http://learnmem.cshlp.org/site/misc/terms.xhtml). After } 12 \text { months, it is available under } \\ \text { a Creative Commons License (Attribution-NonCommercial } 4.0 \text { International), as } \\ \text { described at http://creativecommons.org/licenses/by-nc/4.0/. }\end{array} \\ & \begin{array}{c}\text { Receive free email alerts when new articles cite this article - sign up in the box at the } \\ \text { top right corner of the article or click here. }\end{array} \\ & \begin{array}{c}\text { Service } \\ \text { terting }\end{array}\end{aligned}$

